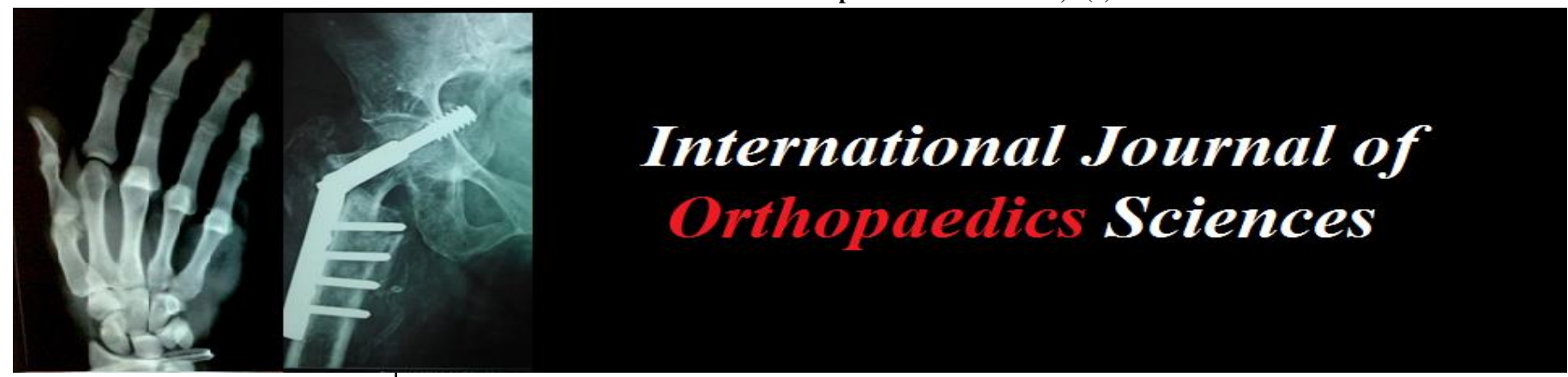

ISSN: $2395-1958$

IJOS 2018; 4(2): 511-517

(C) 2018 IJOS

www.orthopaper.com

Received: 19-02-2018

Accepted: 20-03-2018

Dr. Nirup NC

Department of Orthopaedics,

Sree Balaji Medical College and

Hospital, BIHER, No. 7, Works

Road, New Colony, Chromepet,

Chennai, Tamil Nadu, India

Dr. Venkatachalam K

Department of Orthopaedics,

Sree Balaji Medical College and

Hospital, BIHER, No. 7, Works

Road, New Colony, Chromepet,

Chennai, Tamil Nadu, India
Correspondence

Dr. Venkatachalam K

Department of Orthopaedics,

Sree Balaji Medical College and

Hospital, BIHER, No. 7, Works

Road, New Colony, Chromepet,

Chennai, Tamil Nadu, India

\section{Establishing the efficacy of limb reconstruction system (LRS) in the management of complex long bone non- union: A prospective study}

\section{Dr. Nirup NC and Dr. Venkatachalam K}

DOI: https://doi.org/10.22271/ortho.2018.v4.i2h.79

\section{Abstract}

In an urban metropolitan city like Chennai, over the years there has been a steady increase of high velocity RTA's especially with the number of citizens using two wheelers. In these instances, it is common to encounter communited open long bone fractures of the humerus, tibia and femur. Despite the prompt redressal of these cases with adequate debribment and stabilisation, a significant percentage of these cases land up with recrudescence of infection leading to complex non-unions. Some of these cases end up being operated upon several times with an aim to eradicate the infection, the presence of infection leads to scaring of sub adjacent soft tissue and the repetitive surgical intervention leads to devitalisation of the surviving bone. These complex infective non-union presents with not only with problem of indolent infection but with associated deformity, limb length discrepancy, sub adjacent joint involvement, disuse osteoporosis and soft tissue atrophy, as a consequence they turn out to be a complex challenging orthopaedic situation. These complex non-unions have been over the decades been traditionally addressed by the ilizarov ring fixator systems. In comparison limb reconstruction system which are lighter, less cumbersome and structurally rigid and uniplanar, come in as a significantly suitable alternative. It further has the advantage of distraction at one level and compression at fracture site. It permits dynamization of fracture site which is an essential element in the treatment of any nonunion. In this prospective case series done between March 2015 to October 2017, we have studied 34 cases of patients reporting with complex long bone non-unions by the application of limb reconstruction system. The present study establishes the efficacy of the limb reconstruction system (LRS) in the treatment of these complex non-unions fractures of the long bone. In our series all cases went in for sound union with only $5.72 \%(n=4)$ requiring resurgery.

Keywords: Complex long bone non-union, limb reconstruction system (LRS), compression distraction, bone transport

\section{Introduction}

The Limb Reconstruction System (LRS) is a series of modular monolateral external fixators to be used in reconstructive procedures for the treatment of limb length discrepancy, bone loss, open fractures, non-union and angular deformities ${ }^{[1]}$. Many years of clinical experience have confirmed the efficacy of the device, providing good outcomes for the above indications ${ }^{[2]}$. The innovation in the Advanced LRS has produced improved efficiency; increasing its ease of application in deformity correction, joint contracture and bone transport with short segments. This has expanded the available choices for the surgeon as there is now a system of external fixation for the effective treatment of deformity and bone defects that is better tolerated by the patient ${ }^{[3]}$.

Management of these complex nonunionised in the presence of infection, angular deformity, limb length discrepancy and also multiple previous surgery is a challenging orthopaedic task, that the surgeon faces ${ }^{[4]}$. This disadvantage of ilizarov ring fixator is that it has a poor patient compliance and require frequent surgeon monitoring. This limb reconstruction system (LRS) on the other hand are uniplanar, less bulky and cumbersome further it allows for distraction at one site and compression at the other site ${ }^{[5]}$. It further permits for dynamization of the fracture non-union site, which is the essence of the principle of treatment of non-union ${ }^{[6]}$. The present study incorporates non-union resulting from non-unions of long bone of tibia, femur and humerus, which are both of infective and non-infective. 


\section{Material and Methods}

2.1 Aim of the study: Evaluation of the efficacy, radiological and functional outcome by using limb reconstruction system (LRS) method in the treatment for the management of complex long bone non-union with or without segmental bone loss and with or without active indolent infection.

This is a prospective case series study of complex long bone non-union reporting at the Department of Orthopaedics at Sree Balaji Medical College and Hospital, Chromepet from March 2015 to December 2017. Recruitment of cases stopped in February 2017, so that the follow up time is for a minimum period of 10 months. Hence the study lasted 2 years and 10 months, while the recruitment of patients was for 24 months.

\subsection{Inclusion criteria}

- Both men and women in age group of 20 to 50 years were included in the study.

- Non-union of humerus, femur and tibia both noninfective and infective, with any associated limb length discrepancy or angular deformity, were included in the study.

\subsection{Exclusion criteria}

- Patients not fulfilling the above inclusion criteria were excluded.

- Tuberculous non-unions were excluded.

- Pathological fracture non-unions arising out of skeletal metastasis, were excluded.

- Congenital causes of non-union of fracture were excluded.

- Fracture non-unions resulting from metabolic bone diseases were excluded.

\subsection{Operative Management}

Patient was worked up for surgery by doing all pre-surgical investigations. Anaesthetic fitness for surgery was obtained. Each case was planned depending on radiological diagnosis, soft tissue condition, infective or non-infective status. Patients with bone loss, dead sclerotic or sequestrated bone and limblength discrepancy were planned for excision of the devitalized tissues and the gap was managed by bone transport after a corticotomy at a proximal metaphyseal or metaphyseo - diaphyseal zone, after acute docking at the debrided fracture site. Segmental resection of fibula was done in leg to allow for acute docking. Attention was paid to preserving the periosteum at the coticortomy site because it has a major role in distraction osteogenesis. Sinus tract if any were surgically excised.

Patient was taken under spinal anaesthesia for lower limb non-union fractures and for upper limb non-union fractures, general anaesthesia or suitable regional anaesthesia was adopted. Wound debridement at the fracture non-union site was done meticulously and the bone ends were freshened until active bleeding could be visualised. Necrotic and fibrotic soft tissues in the vicinity of the fracture site were excised. In the presence of active or indolent infection, an antibiotic lavage with metrogyl and gentamycin was given which was followed up with a lavage with povidone iodine solution. Prior to lavage, swab was taken for culture and sensitivity. Monolateral external fixator was applied following this. In cases requiring bone transport the designated site of corticotomy was addressed first before the surgical exploration of the non-union site. The most distal and the proximal schanz screws were applied first and tightened after making sure that the limb is in proper axial and rotational alignment. The remaining schanz screws were secured subsequently. In all the cases acute docking was done at the non-union site and compression given. A C ARM image was taken at the end of the surgery to reconfirm the bony alignment and the bicortical purchase of the schanz screws. Corticotomy for bone transport was opted for only when the expected limb length discrepancy exceeded to $2 \mathrm{~cm}$. In our series of 34 cases, 25 cases had shortening comprising of the designated limit. Shortening is an issue from the functional view point only in the lower limb bones. Shortening of even up to $3 \mathrm{~cm}$ are forgiving in the upper limb arm bone. The operative field was thoroughly irrigated and wound closed by stay suture.

\subsection{Post-op protocol \\ 2.5.1 First phase}

During this first phase care is taken to meticulously do the pin tract dressing. IV antibiotics which were initiated on the day of surgery were continued for 5 days. In instances where gross or indolent infection were detected intra-operatively and sample was sent for culture and sensitivity, depending on the sensitivity report appropriate IV antibiotics were initiated and continued for a period of 3 weeks. The period of distraction is dependent on the extent of shortening present. In our series of 34 cases, 25 cases had a shortening in excess of $2 \mathrm{~cm}$ necessitating a corticotomy at a proximal site and then a subsequent distraction. Shortening of a few $\mathrm{cm}$ of humeral bone were over looked as they had no functional bearing on the outcome. In our series of 25 cases, which required lengthing, 19 cases were of tibia and 6 cases were of femur.

\subsubsection{Second phase}

Distraction was initiated on POD 7. The fixator was always applied to the lateral aspect for femur and the tibia. The distraction procedure was taught by the surgeon to the patient. The aim was to achieve a distraction of $1 \mathrm{~mm}$ per day and this was accomplished by making a quarter of a turn of the distraction nut at fourth hourly intervals, during the waking hours (viz: $8.00 \mathrm{am}, 12.00 \mathrm{pm}, 4.00 \mathrm{pm}$ and $8.00 \mathrm{pm}$ ). Thus a 360 degrees rotation of the distraction nut translates into a $1 \mathrm{~mm}$ distraction at the coticortomy site. Patient is also taught to do pin tract dressings. Toe touch walking with walker support is also initiated from POD 7 or as early as the patients pain tolerance may permit. Thus prior to discharge the patient is ambulant, knowledgeable about the distraction method and also is trained on self-care of the pin tracts which is usually done with sterilium. Usually the patients are discharged by POD 12 with the advise that should there be abnormal pain, numbness or tingling distal to the fixator, the distraction procedure should be stopped forthwith and resumed after 48 hours in increments of two turns, 3 turns and 4 turns over a period of 7 days. Should upon resumption of distraction, if there be any recrudescence of pain or numbness, patient is advised to report immediately to the hospital.

\section{Results}

Table 1: Based on the age and sex of the patients.

\begin{tabular}{|c|c|c|}
\hline Age (In Years) & Male 'N' (Percentage) & Female 'N' (Percentage) \\
\hline $20-24$ & 2 & 1 \\
\hline $25-29$ & 3 & 2 \\
\hline $30-34$ & 4 & 1 \\
\hline $35-39$ & 7 & 1 \\
\hline $40-44$ & 5 & 0 \\
\hline $45-50$ & 5 & 3 \\
\hline Total & $26(76.47 \%)$ & $8(23.53 \%)$ \\
\hline
\end{tabular}


Table 2: Patient's particulars.

\begin{tabular}{|c|c|c|c|}
\hline \multicolumn{2}{|c|}{ Charecteristics } & "n” & Percentage \% \\
\hline \multirow{2}{*}{ Gender } & Male & 26 & 76.47 \\
\cline { 2 - 4 } & Female & 8 & 23.53 \\
\hline \multirow{2}{*}{ Sidedness Of Fracture } & Left & 14 & 41.18 \\
\cline { 2 - 4 } & Right & 20 & 58.82 \\
\hline \multirow{2}{*}{ Nature Of Fracture } & Closed & 6 & 17.65 \\
\cline { 2 - 4 } & Open & 28 & 82.35 \\
\hline \multirow{3}{*}{ Mode Of Injury } & Rta & 26 & 76.47 \\
\cline { 2 - 4 } & Fall From Height & 6 & 17.65 \\
\cline { 2 - 4 } & Fall From Ladder & 2 & 5.88 \\
\hline
\end{tabular}

Table 3: Nature and anatomical site of the complex non-union.

\begin{tabular}{|c|c|c|c|}
\hline \multicolumn{2}{|c|}{ Chrecteristics } & “n” & $\begin{array}{c}\text { Percentage } \\
\%\end{array}$ \\
\hline \multirow{3}{*}{$\begin{array}{l}\text { Level of } \\
\text { Non Union }\end{array}$} & Upper $1 / 3^{\text {rd }}$ & 3 & 8.82 \\
\hline & Middle $1 / 3^{\text {rd }}$ & 25 & 73.53 \\
\hline & Lower $1 / 3^{\text {rd }}$ & 6 & 17.65 \\
\hline \multirow{5}{*}{$\begin{array}{l}\text { Nature of } \\
\text { Complex } \\
\text { Non Union }\end{array}$} & $\begin{array}{c}\text { Infected Non-Union With } \\
\text { Draining Sinus }\end{array}$ & 23 & 67.64 \\
\hline & $\begin{array}{l}\text { Infected Non-Union } \\
\text { Without Sinus }\end{array}$ & 5 & 14.72 \\
\hline & $\begin{array}{l}\text { Non-Infected Bone Defect } \\
\text { Non Union }\end{array}$ & 3 & 8.82 \\
\hline & Elephant Foot Non-Union & 2 & 5.88 \\
\hline & Oligotrophic Non-Union & 1 & 2.94 \\
\hline
\end{tabular}

Table 4: Characteristics.

\begin{tabular}{|c|c|c|c|}
\hline \multirow{2}{*}{ Particulars } & In Months & “N” & $\begin{array}{c}\text { Percentage } \\
\text { \% }\end{array}$ \\
\hline \multirow{3}{*}{$\begin{array}{c}\text { Mean Duration } \\
\text { Of Non Union }\end{array}$} & $6-7$ & 4 & 11.76 \\
\cline { 2 - 4 } & $7-8$ & 5 & 14.70 \\
\cline { 2 - 4 } & $8-9$ & 9 & 26.49 \\
\hline \multirow{2}{*}{$\begin{array}{c}\text { Long Bone } \\
\text { Involvement }\end{array}$} & $9-10$ & 16 & 47.05 \\
\cline { 2 - 4 } & Tibia & 24 & 70.58 \\
\hline \multirow{3}{*}{ Lrs Usage Mode } & Humerus & 4 & 11.77 \\
\cline { 2 - 4 } & Femur & 6 & 17.65 \\
\cline { 2 - 4 } & $\begin{array}{c}\text { Compression } \\
\text { Distraction }\end{array}$ & 6 & 17.64 \\
\cline { 2 - 4 } & $\begin{array}{c}\text { Compression And } \\
\text { Bone Transport }\end{array}$ & 25 & 73.54 \\
\hline
\end{tabular}

Table 5: Complication.

\begin{tabular}{|c|c|c|}
\hline Problem & "N" & Percentage \% \\
\hline Pin Tract Infection & 22 & 31.88 \\
\hline Pin Loosening & 10 & 14.49 \\
\hline Joint Stiffness & 17 & 24.63 \\
\hline Angulation & 7 & 10.14 \\
\hline Premature Union Of Corticotomy Site & 2 & 2.89 \\
\hline Persistant Discharge & 2 & 2.89 \\
\hline Equinus & 9 & 13.04 \\
\hline Refracture & 2 & 2.89 \\
\hline
\end{tabular}

Table 6: Mean distraction done over the long bones.

\begin{tabular}{|c|c|c|c|c|c|c|}
\hline $\begin{array}{c}\text { Shortening } \\
\text { In Mm }\end{array}$ & \multicolumn{4}{|c|}{ Mean Distraction } & \multicolumn{2}{c|}{ Total } \\
\hline & $\begin{array}{c}\text { Femur } \\
\text { (N) }\end{array}$ & (Days) & $\begin{array}{c}\text { Tibia } \\
\text { (N) }\end{array}$ & (Days) & N & $\%$ \\
\hline $2-2.4$ & 1 & 35 & 3 & 38 & 4 & 37.25 \\
\hline $2.5-2.9$ & 1 & 42 & 2 & 46 & 3 & 44.66 \\
\hline $3-3.4$ & 2 & 51 & 3 & 58 & 5 & 55.2 \\
\hline $3.5-3.9$ & 1 & 59 & 5 & 64 & 6 & 63.16 \\
\hline $4-4.4$ & 1 & 70 & 6 & 75 & 7 & 74.28 \\
\hline Total & 6 & & 19 & & 25 & \\
\hline
\end{tabular}

Table 7: Mean period taken for fracture healing for lower limb bone.

\begin{tabular}{|c|c|c|}
\hline Time Taken In Weeks & Tibia & Femur \\
\hline $35-37$ & 1 & 0 \\
\hline $38-40$ & 3 & 1 \\
\hline $41-43$ & 9 & 1 \\
\hline $44-46$ & 7 & 3 \\
\hline $47-49$ & 4 & 1 \\
\hline Total & 24 & 6 \\
\hline
\end{tabular}

Table 8: Mean period of fracture healing for upper limb bone.

\begin{tabular}{|c|c|}
\hline Time In Weeks & Humerus \\
\hline $25-26$ & 1 \\
\hline $26-27$ & 2 \\
\hline $27-28$ & 1 \\
\hline Total & 4 \\
\hline
\end{tabular}

In the 24 months of recruitment we could enrol 34 patients who satisfied our inclusion criteria. Of these 34 patients, there were $76.47 \%(n=26)$ males and $23.53 \%(n=8)$ females. There was a preponderance of right sidedness of the fracture nonunions at $58.82 \%(\mathrm{n}=20)$ among these 34 cases the primary fracture was a open fracture in $82.35 \%(\mathrm{n}=28)$. Again majority of the injuries $76.47 \%(n=26)$ were as a result of road traffic accident.

Most of the non-unions treated in this series involved the middle $1 / 3^{\text {rd }}$ of the long bone at $73.53 \%(n=25)$ followed by fracture of the lower $1 / 3^{\text {rd }}$ at $17.65 \%(n=6)$. Majority of these non-unions $82.36 \%(\mathrm{n}=28)$ were those with indolent or frank infection at the non-union site with or without sinus only $17.64 \%(n=6)$ were of the noninfective type.

Majority of the non-unions in our series $70.58 \%(n=24)$ were of tibia, $17.35 \%(n=6)$ were of femur and $11.77 \%(n=4)$ were of the humerus. The mean time lapse of the non-unions dealt with this series were 8.6 months (range: 6 months to 10 months). The LRS usage mode was $73.54 \%(n=25)$ as a compression and bone transport mode. In the remaining $26.46 \%(n=9)$ the LRS usage mode was either in pure compression mode or in the compression distraction mode.

Among the complications encountered the highest were in the form of pin tract infection at $31.88 \% \quad(n=22)$, this was followed at $24.63 \%(n=17)$ as joint stiffness and another $14.49 \%(n=10)$ as pin loosening. We had $2.89 \%(n=2)$ of premature union of coticortomy site where distraction had been withheld for about 4 weeks due to nerve palsy, which required surgical refreshment of the coticortomy site. We also had $2.8 \%(n=2)$ of refracture at the distracted site because of early weight bearing by the patient after fixator removal. These 2 cases however could be managed conservatively by the application of PTB cast.

In our series majority of the patients $58.80 \%(n=20)$ where in the age group of $35-50$ years. The remaining $41.20 \%(n=12)$ where in the age group of 20-34 years. In cases requiring coticortomy and bone transport the number of days were proportionate to the amount of shorting. The mean number of days were maximum at $74.28 \%$ for a shortening of 4 to $4.4 \mathrm{~cm}$. Our series included cases where the shortening ranged from 2 to $4.4 \mathrm{~cm}$, of these 19 involved that of tibia and 6 involved that of femur. 


\section{Case illustration}

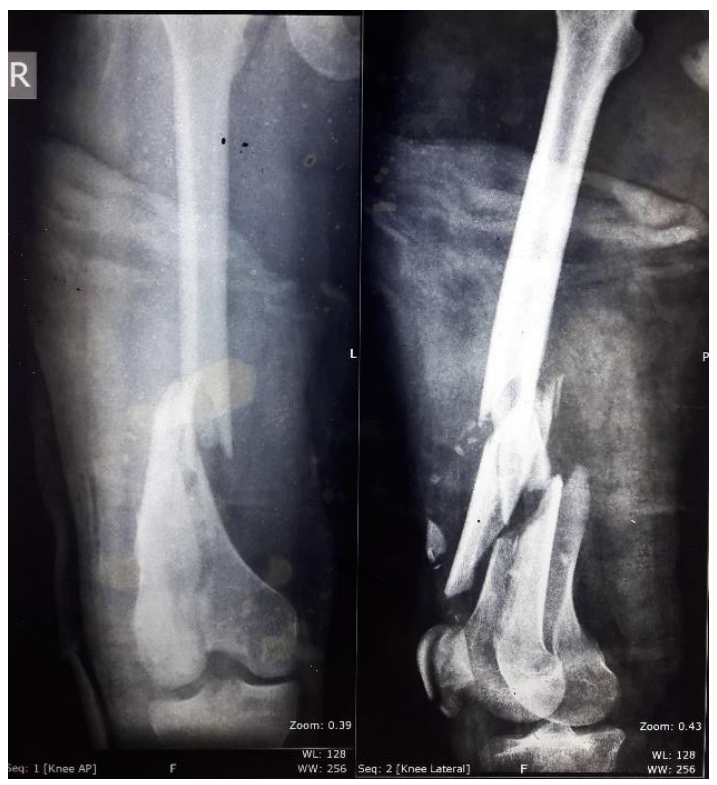

Fig 1a: Fracture of lower $1 / 3^{\text {rd }}$ of femur right side.

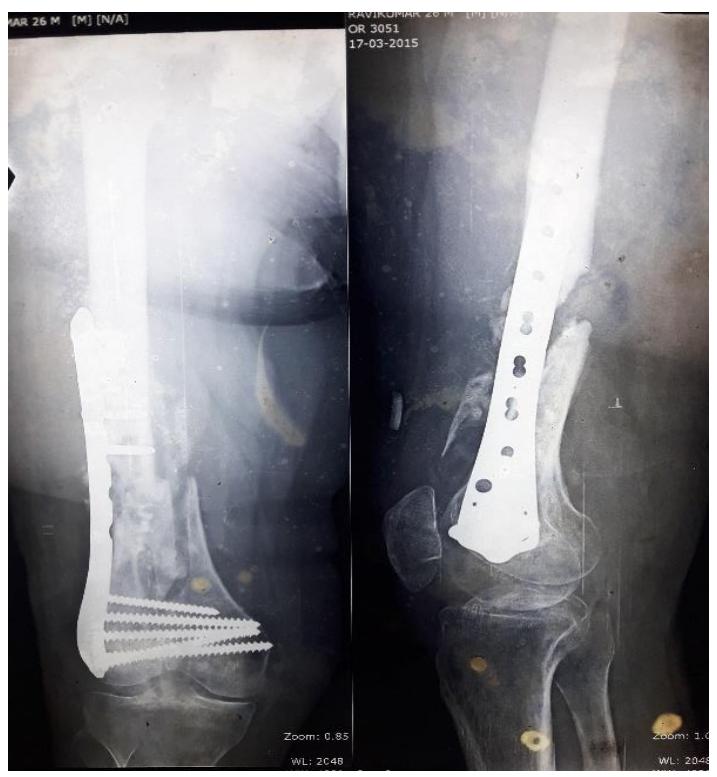

Fig 1b: Showing failed plating system resulting in non union.

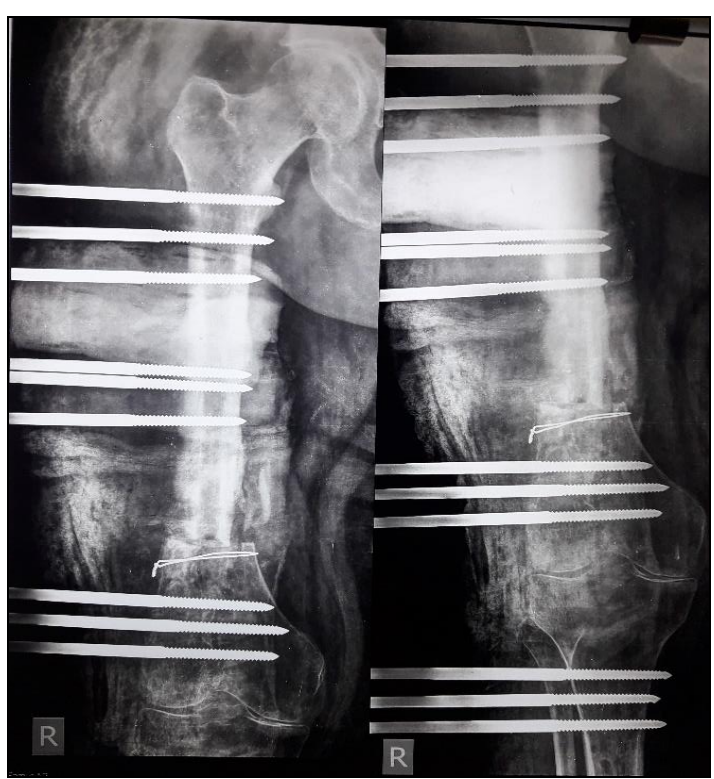

Fig 1c: Showing 6 months after distraction with LRS in situ.

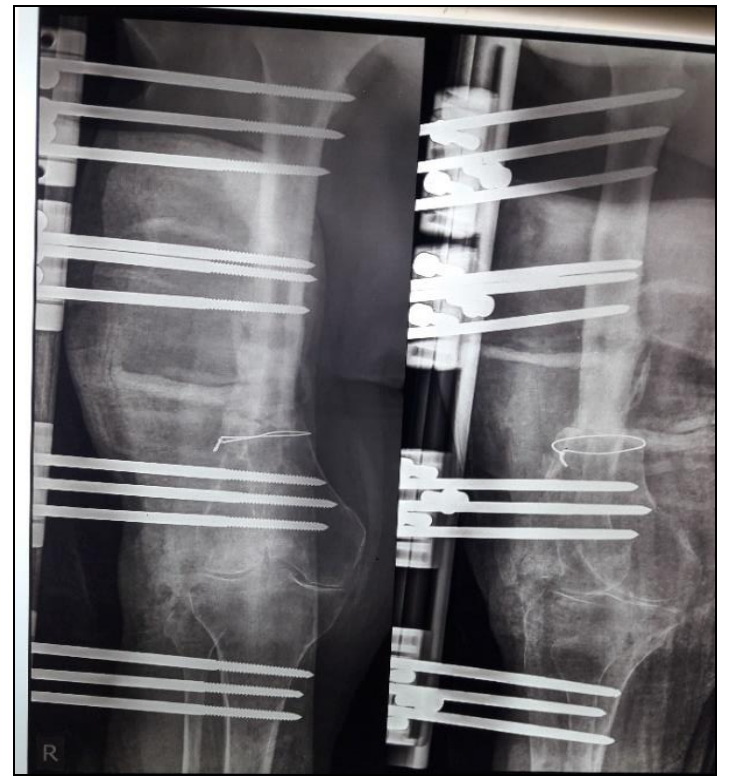

Fig 1d: Showing adequate callus formation at 9 months.

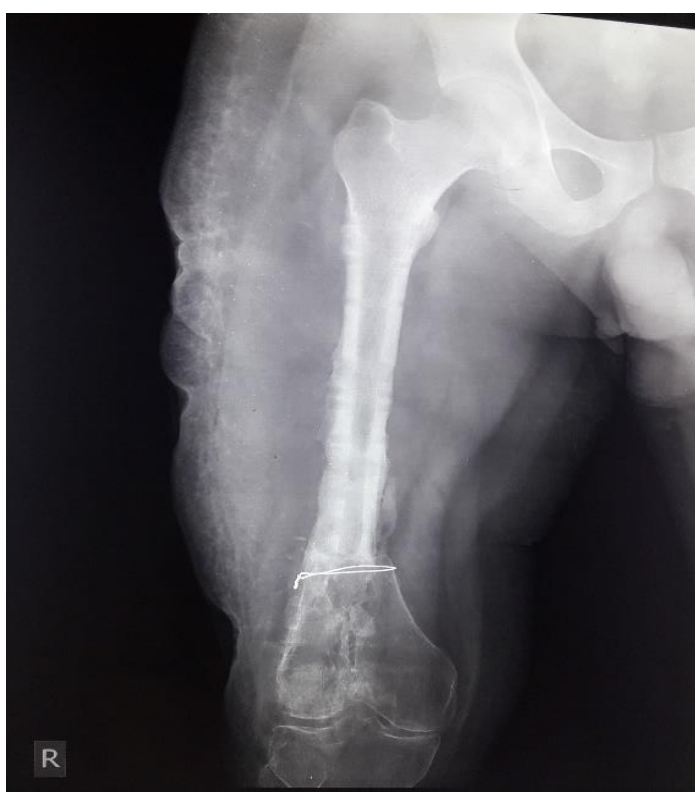

Fig 1e: Showing fracture union at 10 months.
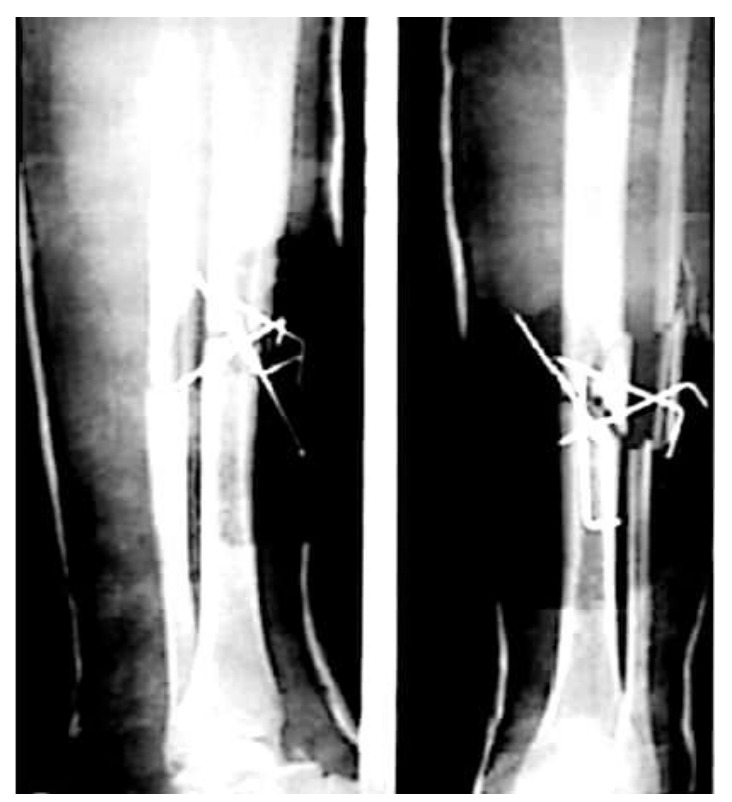

Fig 2a: Showing fracture of both bone of right leg with implant failure and non-union. 


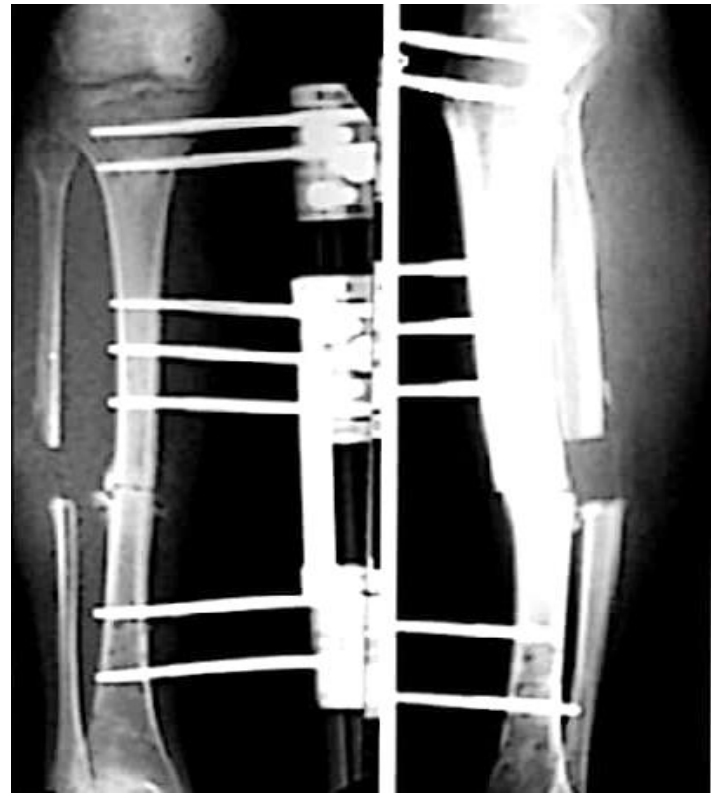

Fig 2b: Showing LRS over right tibia with fibulectomy.

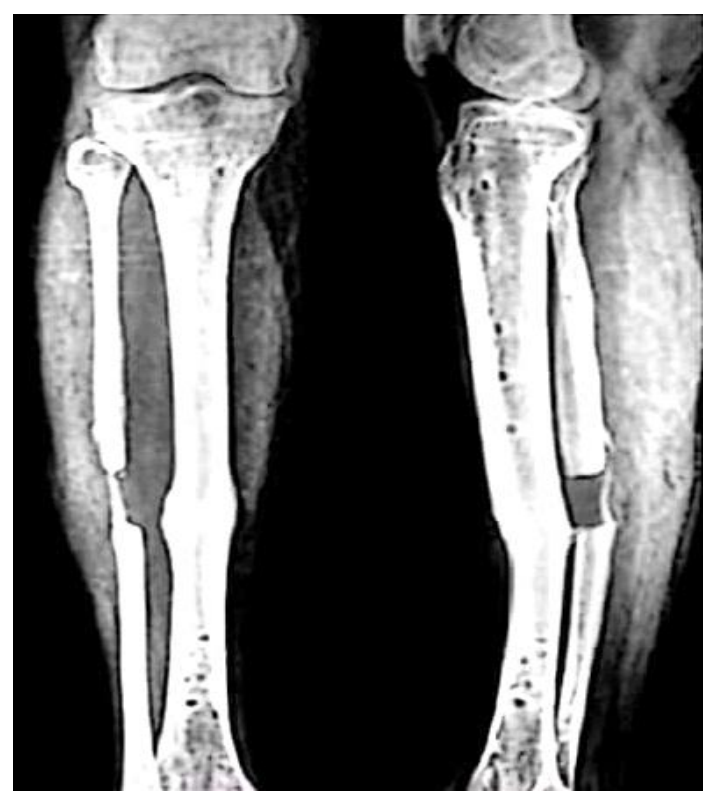

Fig 2c: Showing fracture union of right tibia after LRS is removed at 6 months.

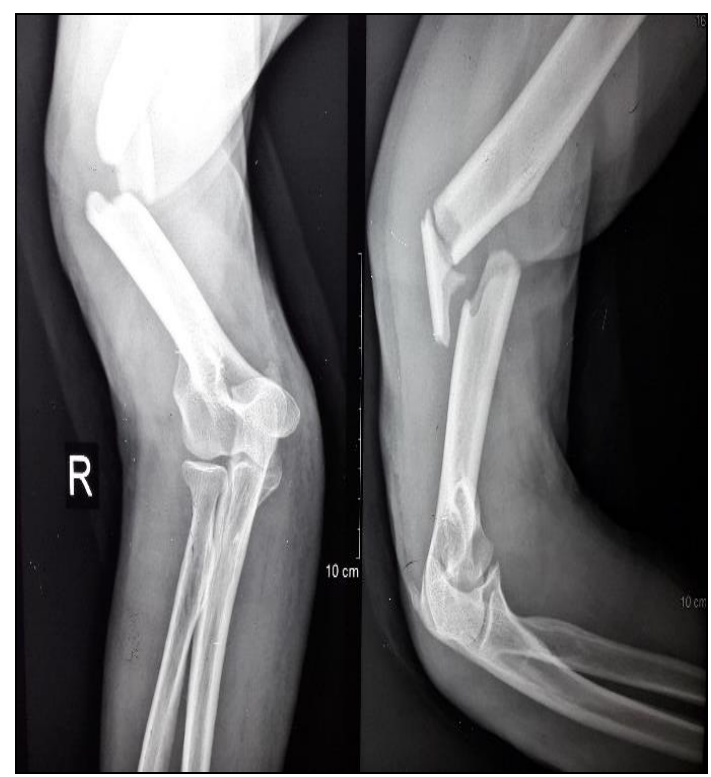

Fig 3a: Showing fracture mid shaft of right humerus.

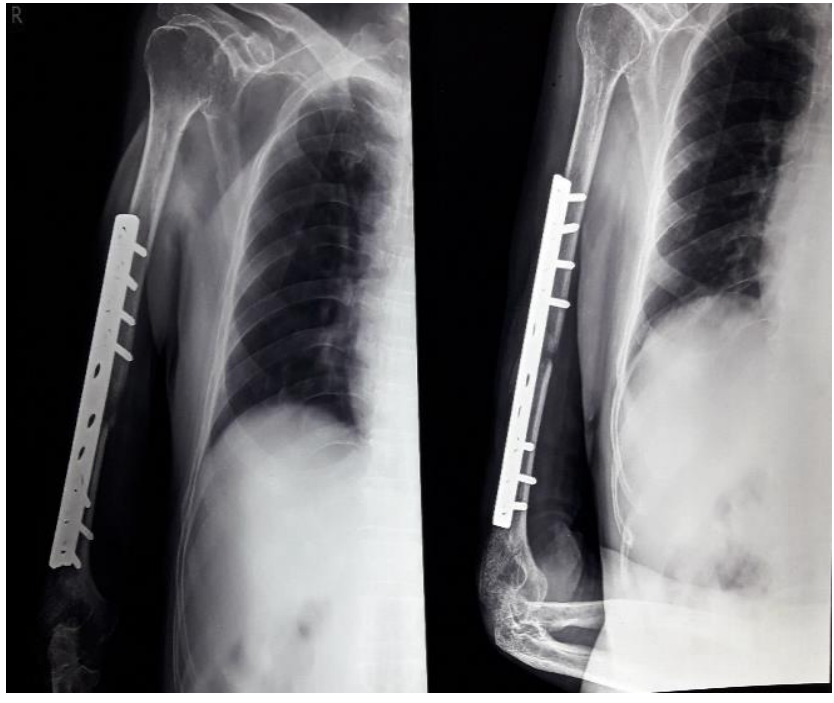

Fig 3b: Showing non union fracture shaft of right humerus with infected implant in situ.

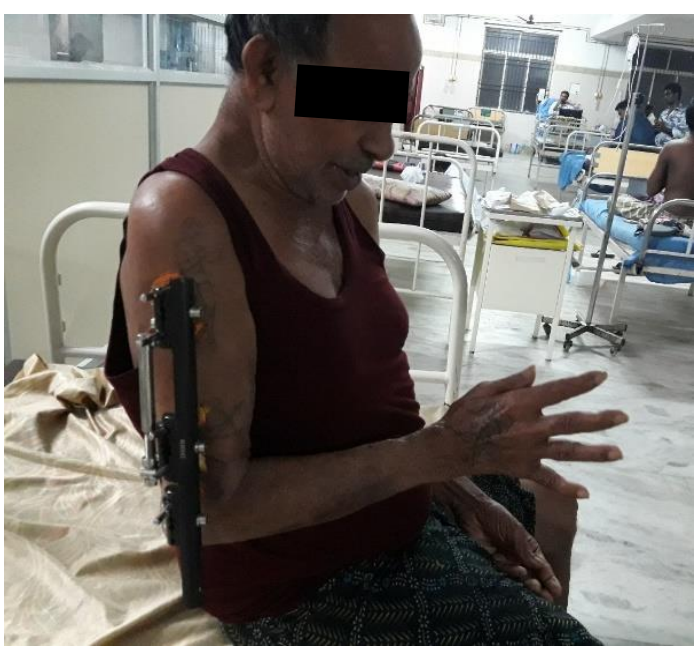

Fig 3c: Showing patient after LRS fixator application.

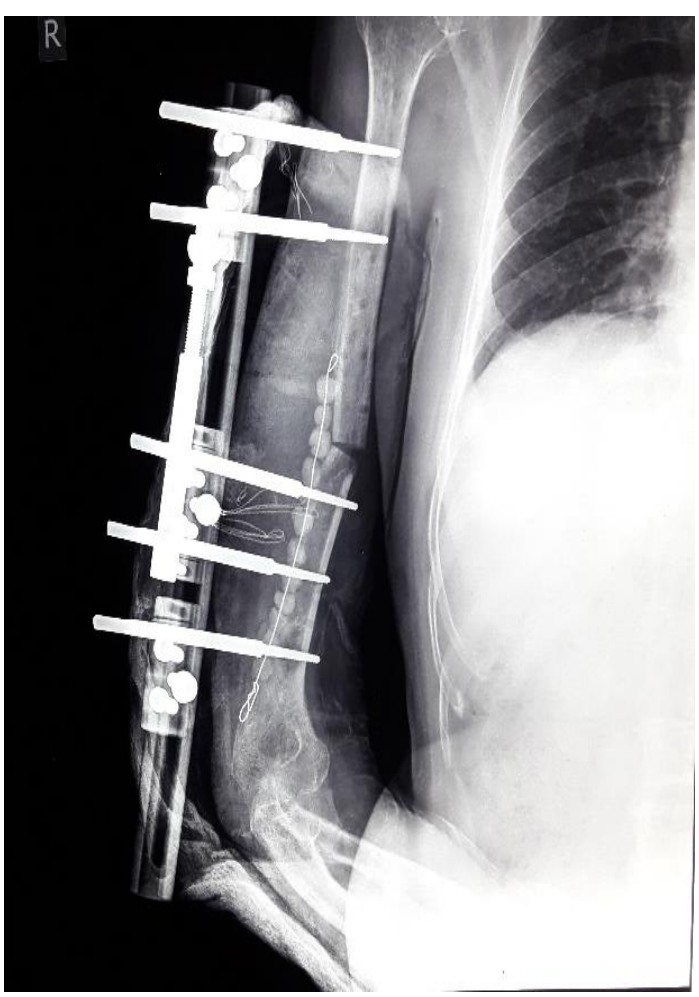

Fig 3d: Showing fracture shaft of humerus after implant removal with antibiotic beads and LRS fixator in situ. 


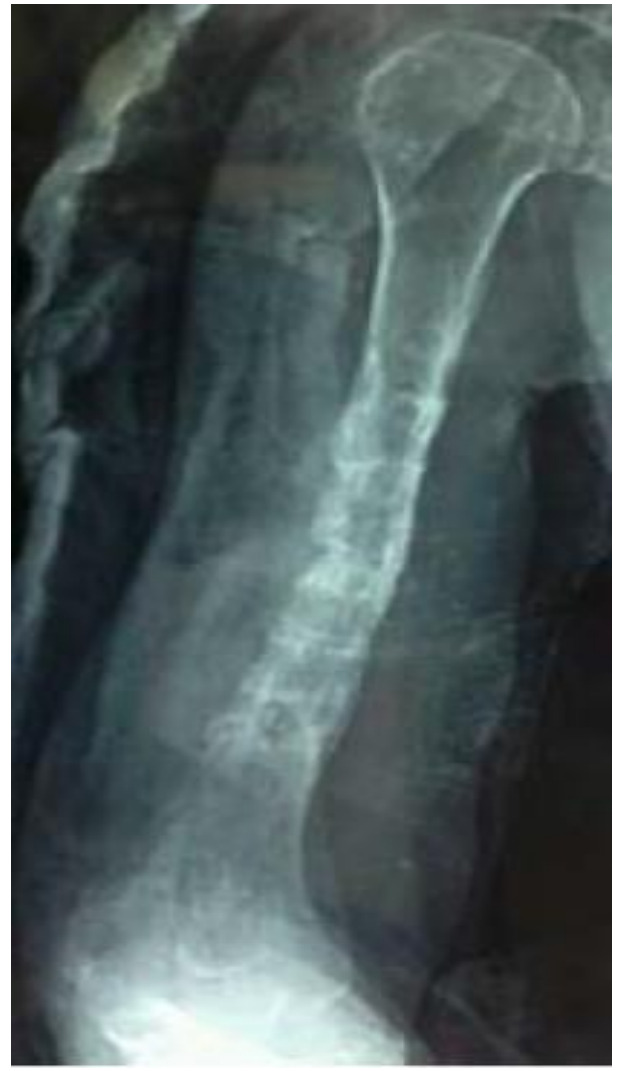

Fig 3e: X ray Showing united fracture shaft of right humerus at 6 months.

\section{Discussion}

In the present day scenario incidence of long bone fractures have increased due to rise in road traffic accidents. These fractures in many an instances, go in for complex non-unions, some requiring prolonged treatment and sometimes even multiple surgeries. In the instance of the original fracture being open, the chances are that we have to deal with an infective non-union. Repetitive surgeries and the presence of infection produces scaring of soft tissues and devitalization of the remaining bone. Indolent infection are almost invariably present also with other complications such as deformity, limb shortening, adjacent joint stiffness, disuse atrophy of the muscles and disuse osteoporosis of the injured bone ${ }^{[7]}$. All these problems make it a challenging task for the orthopaedic surgeon ${ }^{[8]}$. It is in managing this herculean task, that the external fixators come as a boon, as they are able to address all these problems simultaneously [9, 10]. From the 90's onwards complex, non-unions, whether infected or otherwise were managed surgically with ilizarov external ring fixator system. But the disadvantages in it lies with the fact that they are cumbersome heavy and complicated, from the patients point of view ${ }^{[11]}$. The limb reconstruction system on the other hand are uniplanar and therefore less bulky. These have an added advantage of allowing for distraction at coticortomy site and compression at fracture site, which allows for correction of any limb length discrepancy simultaneously.

The limb reconstruction system allows also for dynamization of the fracture site with micro motion which is the essential component in the treatment of fracture non unions ${ }^{[12]}$. LRS is mechanically a stable construct and the presence of sliding clamps allows for a variable spread of fixation. In our series of 34 patients there was a male preponderance of $76.47 \%$ $(\mathrm{n}=26)$. This compares well with the study of Hiranya Kumar Seenappa et al., who reported a male preponderance of $93 \%$. Our incidence of $76.47 \%$ compares well with that of Seenappa's study of $83 \%$ as RTA being the predominant mechanism of injury. In our series majority of the non-unions $70.58 \%$ were of the tibia, which when compared to Seenappa's was $54 \%$. Tibial bone being a subcutaneous bone for more than half its length, is more prone for open fracture. Most of our humeral fractures healed by a mean of 5.8 months which compares well with the series of Seenappa's where it was reported as 6.2 months. In our series tibial non-unions took a mean of 9.9 months and femoral non-unions took a mean of 10.4 months. There was 1 case of radial nerve palsy which recovered in 6 weeks and hence was not recorded as a complication. In view of the monolateral axial fixator, in the shoulder series, mobilization of the shoulder and elbow was possible as early as two weeks and hence there were no significant residual joint stiffness. However there were 10 cases of ankle stiffness and 7 cases of knee stiffness in the lower limb series, but a majority of these cases had the stiffness prior to LRS fixation.

In our series union rate was $100 \%$. Among them $17.46 \%$ was by primary union, $8.82 \%$ was by callus distraction compression and $73.54 \%$ by bone transport. In cases of shortening of less than $2 \mathrm{~cm}$, in which coticortomy and bone transport was not performed in the lower limb series, for them a shoe rise was given.

Table 9: Comparison of our results with other studies. (Based on ASAMI scoring system) ${ }^{[13]}$.

\begin{tabular}{|c|c|c|c|c|c|c|}
\hline Result & \multicolumn{2}{|c|}{ Our Study LRS } & \multicolumn{2}{c|}{ Hiranya Kumar Seenappa et al., LRS ${ }^{[14]}$} & \multicolumn{2}{c|}{ Hashmi et al., LRS ${ }^{[15]}$} \\
\hline Bony Results & $\mathrm{N}$ & $\%$ & $\mathrm{~N}$ & $\%$ & $\mathrm{~N}$ & $\%$ \\
\hline Excellent & 12 & 35.29 & 22 & 79 & 67 & 61 \\
\hline Good & 17 & 50 & 03 & 11 & 38 & 35 \\
\hline Fair & 5 & 14.70 & 0 & 10 & 04 & 03 \\
\hline Poor & 0 & & 03 & & 0 & 0 \\
\hline Functional Results & & & & 40 & 46 & 42 \\
\hline Excellent & 15 & 44.11 & 11 & 50 & 55 & 55 \\
\hline Good & 17 & 50 & 14 & & 4 & 3 \\
\hline Fair & 2 & 5.88 & 0 & & 0 & \\
\hline Poor & 0 & & 0 & 10 & 5 & 5 \\
\hline Failure & 0 & & 03 & & & \\
\hline
\end{tabular}

Our bony results as per ASAMI scoring did not match with neither Hiranya et al., ${ }^{[14]}$ nor that of Hasmi et al., ${ }^{[15]}$ but surprisingly the functional results are a near perfect match in all the three studies. This proves the point that in the ASAMI scoring system [13] the bony results do not reflect the functional results and hence needs to be taken cognisance of.

\section{Conclusion}

Limitation of our study is in the fact that we did not have a control group or a comparision study with ilizarov technique. Also the ratio of male to female cases was grossly tilted in favour of the former at 3:1. With the above given limitations and the relatively small number of cases $(n=34)$, our 
experience with LRS has been gratifying for complex long bone nonunions which are either infected or not by achieving a union rate of $100 \%$. Patient satisfaction and compliance during the entire course of treatment was excellent.

\section{Reference}

1. Cleveland Kevin B. Delayed Union and Nonunion of Fractures, chapter 56, Campbell's Operative Orthopaedics: $11^{\text {th }}$ edition, Mosby Elsevier, Philadelphia, Pennsylvania, USA. 2008; 3:3533.

2. Charles M, Court- Brown. Ed, Fracture of The tibia and fibula; chapter 52, Rockwood and Green's fractures in adults: $6^{\text {th }}$ edition, Section 4, Lippincott Williams and Wilkins, Philadelphia, USA. 2006; 2:2113.

3. Hashmi MA, Ali A, Saleh M. Management of non-unions with mono-lateral external fixation. Injury. Supplement. 2001; 32(4):30-34.

4. Lavini Franco, Renzi Lodovico Brivio, Pizzoli Andrea. Treatment of non-union of the humerus using the Orthofix external fixator. Injury, Supplement. 2001; 32(4):35-40.

5. Banks JV, Panchanni S, Davies B. Bifocal treatment for femoral nonunions. Journal of Bone and Joint Surgery (Br), 2009; 92B(III):403.

6. Bassiony Ayman A, Almoatasem Alhosain M, Abdelhady Amro M. Infected non-union of the Humerus after Failure of Surgical Treatment: Management using the Orthofix External Fixator. Ann Acad Med Singapore. 2009; 38:1090-4.

7. Dendrinos GK, Konto S, Lyritsis E. Use of Ilizarov technique for treatment of nonunion of tibia associated with infection. J Bone joint Surg Br. 1995; 77 B:835-46.

8. Motsitsi NS. Management of infected nonunion of long bone: The last decade (1996-2006). Injury, 2008; 39:15560.

9. Royston S. Management of nonunion of fractures by distraction with correction of angulation and shortening. $\mathbf{J}$ Bone Joint Surg Br. 1996; 78B:105-9.

10. Saleh RA. Bifocal surgery for deformity and bone loss after lower limb fracture. J Bone Joint Surg Br. 1995; 77B:429-34.

11. Paley D. Problems, Obstacles and complications of limb lengthening by the Ilizarov technique. Clin orthop Relat Res. 1990; 250:81-104.

12. Watson TJ. Principles of External Fixation. Chapter 8, Rockwood and Green's fracture in adults. 7th ed. Sec 1. Philladelphia. USA: Lippincott Williams and Wilkins Publisher. 2010; 1:191-243.

13. Priyajit Chattopadhyay. Treatment of Difficult Nonunion of Long Bones using the Ilizarov Technique. International journal of scientific study. 2017; 4(12):2730.

14. Hiranya Kumar Seenappa. Management of complex long bone nonunions using limb reconstruction system.

15. Hashmi MA, Ali A, Saleh M. Management of nonunion with monolateral external fixation. Injury. 2001; 32:30-4. 